\title{
Extracorporeal membrane oxygenation in adult patients with hematologic malignancies and severe acute respiratory failure
}

\author{
Philipp Wohlfarth', Roman Ullrich², Thomas Staudinger ${ }^{1}$, Andja Bojic ${ }^{1}$, Oliver Robak', Alexander Hermann ${ }^{1}$, \\ Barbara Lubsczyk ${ }^{2}$, Nina Worel ${ }^{3}$, Valentin Fuhrmann ${ }^{4}$, Maria Schoder ${ }^{5}$, Martin Funovics ${ }^{5}$, Werner Rabitsch?, \\ Paul Knoebl ${ }^{1}$, Klaus Laczika', Gottfried J Locker ${ }^{1}$, Wolfgang R Sperr ${ }^{1}$, Peter Schellongowski ${ }^{1 *}$ and Arbeitsgruppe \\ für hämato-onkologische Intensivmedizin der Österreichischen Gesellschaft für Internistische und Allgemeine \\ Intensivmedizin und Notfallmedizin (ÖGIAIN)
}

\begin{abstract}
Introduction: Acute respiratory failure (ARF) is the main reason for intensive care unit (ICU) admissions in patients with hematologic malignancies (HMs). We report the first series of adult patients with ARF and HMs treated with extracorporeal membrane oxygenation (ECMO).

Methods: This is a retrospective cohort study of 14 patients with HMs (aggressive non-Hodgkin lymphoma (NHL) $n=5$; highly aggressive NHL, that is acute lymphoblastic leukemia or Burkitt lymphoma, $n=5$; Hodgkin lymphoma, $n=2$; acute myeloid leukemia, $n=1$; multiple myeloma, $n=1$ ) receiving ECMO support because of ARF (all data as medians and interquartile ranges; age, 32 years (22 to 51 years); simplified acute physiology score II (SAPS II): 51 (42 to 65$)$ ). Etiology of ARF was pneumonia $(n=10)$, thoracic manifestation of NHL $(n=2)$, sepsis of nonpulmonary origin $(n=1)$, and transfusion-related acute lung injury $(n=1)$. Diagnosis of HM was established during ECMO in four patients, and five first received (immuno-) chemotherapy on ECMO.

Results: Before $\mathrm{ECMO}$, the $\mathrm{PaO}_{2} / \mathrm{FiO}_{2}$ ratio was 60 (53 to 65), (3.3 to 3.7). Three patients received venoarterial ECMO because of acute circulatory failure in addition to ARF; all other patients received venovenous ECMO. All patients needed vasopressors, and five needed hemofiltration. Thrombocytopenia occurred in all patients (lowest platelet count was 20 (11 to 21) G/L). Five major bleeding events were noted. ECMO duration was 8.5 (4 to 16) days. ICU and hospital survival was 50\%. All survivors were alive at follow-up (36 (10 to 58) months); five patients were in complete remission, one in partial remission, and one had relapsed.
\end{abstract}

Conclusions: ECMO therapy is feasible in selected patients with HMs and ARF and can be associated with long-term disease-free survival.

\section{Introduction}

The acute respiratory failure (ARF) represents the predominant reason for medical intensive care unit (ICU) admissions in patients with hematologic malignancies (HMs) [1-5]. Its occurrence has a strong prognostic impact, especially if mechanical ventilation becomes necessary. Although the outcome of those affected was

\footnotetext{
* Correspondence: peter.schellongowski@meduniwien.ac.at

'Department of Medicine I, Intensive Care Unit 13i2, Comprehensive Cancer Center, Medical University of Vienna, Waehringer Guertel 18-20, A-1090 Vienna, Austria

Full list of author information is available at the end of the article
}

described to be dismal in the past, survival improved markedly in recent years. This development may be attributed to advances in patient selection [6], general improvements in the management of the acute respiratory distress syndrome (ARDS), as well as specific improvements in managing ARF in patients with HMs. The latter comprises specific diagnostic algorithms in ARF of HM patients [7], as well as the use of noninvasive ventilation early in the course, even though the efficacy of this procedure does not remain undisputed [8-11]. However, mortality rates of patients with HMs 
and invasive mechanical ventilation due to ARF still exceed $50 \%$ [1,3-5]. Yet, a general reluctance to admit critically ill patients with HMs cannot be justified. Unlimited intensive care has been advocated for selected patients with HMs [12,13].

The extracorporeal membrane oxygenation (ECMO) depicts one of the ultimate therapies in intensive care and may possibly be beneficial in patients with ARDS in general ICU populations $[14,15]$. Some data exist on the use of ECMO in cohorts of children with malignant diseases $[16,17]$, but the published experience with ECMO in adult patients with HM is limited to two single cases $[18,19]$. Because both, patients with HMs and those undergoing ECMO are prone to acquire severe complications, such as bleeding and infection [1,5,20-23], performing ECMO in patients with HMs might bear a particularly high risk.

The purpose of this analysis is to report the characteristics and outcomes of patients with HMs and ARF treated with ECMO.

\section{Materials and methods}

We retrospectively studied the clinical courses of all adult patients (18 years or older) with HMs and ARF treated with ECMO at the Medical University of Vienna, General Hospital, between September 2000 and June 2013. This study was conducted in accordance with the amended Declaration of Helsinki. The ethics committee of the Medical University of Vienna approved the protocol and waived the need for informed consent because of the noninterventional retrospective design of the investigation.

The presence of ARDS was defined and graded according to recently introduced criteria [24]. The term baseline refers to the time immediately before the start of ECMO treatment. Thrombocytopenia was defined as platelet count $<150 \mathrm{G} / \mathrm{L}$, and leukocytopenia as leukocyte count $<4 \mathrm{G} / \mathrm{L}$.

In our center, extracorporeal lung support is usually evaluated in patients presenting with severe and life-threatening hypoxemia while being mechanically ventilated with adequately high positive end-expiratory pressure (PEEP) and a missing response to supportive measures like prone positioning. During ECMO, a maximally achievable protective ventilation setting is desired. Weaning from ECMO is performed according to current Extracorporeal Life Support Organization (ELSO) guidelines [25].

At baseline, we recorded age, gender, characteristics of the hematologic malignancy, including type and stage of the respective malignancy, time of diagnosis, type and timing of previous specific treatments (that is, chemo-, immuno-, or radiotherapy, autologous or allogeneic stem cell transplantation (ASCT)), as well as the intention of cancer treatment (curative versus noncurative). The Charlson Comorbidity Index [26] (CCI) was assessed to account for comorbid conditions. To grade the severity of illness, we calculated the Simplified Acute Physiology Score II (SAPS II) $[27,28]$ at ICU admission, as well as the Sequential Organ Failure Assessment (SOFA) score [29] at baseline, respectively. We determined the etiology of ARF and recorded arterial blood gas parameters $\left(\mathrm{pH}\right.$, partial pressures of oxygen $\left(\mathrm{PaO}_{2}\right)$ and carbon dioxide $\left(\mathrm{PaCO}_{2}\right)$, lactate), $\mathrm{PaO}_{2} / \mathrm{FiO}_{2}$ ratio, the Lung Injury Score (LIS) [30], laboratory tests such as white blood cell count, platelet count, hemoglobin, prothrombin time, and fibrinogen, all at baseline, eventually.

As follow-up variable, we recorded type of ECMO (that is, venovenous (VV) versus venoarterial (VA), use of anticoagulants, vasopressors, and blood products, duration of ECMO therapy, length of ICU and hospital stay, bleeding complications (occurrence, location, and severity), other procedure-related complications (trauma or bleeding related to the insertion of cannulas, clotting events), ICU and hospital survival, course of the malignancy (remission status), death date (if applicable), as well as date of the last visit. Bleeding was considered to be major in patients with a decrease in hemoglobin levels $>2.0 \mathrm{~g} / \mathrm{dl}$ or requiring more than 2 units of packed red blood cells due to an obvious bleeding event, surgical interventions, or in cases of intracerebral hemorrhage. In patients with more than one episode of ECMO, baseline parameters and definite outcomes associated with the last respective ECMO episode were analyzed, whereas for calculation of total ECMO days, all episodes were counted.

Continuous data are presented as median and interquartile ranges ( $25 \%$ to $75 \%)$, unless otherwise indicated. Dichotomous data are presented as number and percentage. Data were compared between survivors and nonsurvivors with Fisher Exact test for dichotomous variables, and the Mann-Whitney $U$ Test for continuous variables, respectively. Differences were considered to be statistically significant when $P$ was $<0.05$.

\section{Results}

We report on 14 consecutive patients with $\mathrm{HMs}$ and ARF treated a total number of 17 ECMO episodes. The male/female ratio was $8: 6$, age 32 years (22 to 51 years), CCI 2 (2 to 2 ) and SAPS II 51 (42 to 65), respectively. The individual characteristics of patients (numbers 1 to 14) are given in Table 1. During the observational period, 541 patients with HMs were admitted to our ICU, of whom 368 (68\%) presented with respiratory failure requiring invasive mechanical ventilation. Thus, the proportion of HM patients with ARF receiving ECMO therapy was $3.8 \%$.

\section{Hematologic malignancy}

The underlying HMs were various types of aggressive non-Hodgkin lymphoma (NHL) in five patients (diffuse 
Table 1 Individual characteristics and outcomes

\begin{tabular}{|c|c|c|c|c|c|c|c|c|}
\hline Patient number & Malignancy & $\begin{array}{l}\text { Therapy status } \\
\text { (days since therapy) }\end{array}$ & $\begin{array}{l}\text { Etiology } \\
\text { of ARF }\end{array}$ & SAPS II & LIS & ECMO days & Bleeding & $\begin{array}{l}\text { ICU and hospital } \\
\text { outcome }\end{array}$ \\
\hline 1 & CNS NHL & Chemotherapy (51) & Pneumonia & 45 & 3.7 & 9 & Minor & Died \\
\hline 2 & Hodgkin lymphoma & Allo SCT (111) & Pneumonia & 34 & 3.3 & $28^{\mathrm{b}}$ & Major & Died \\
\hline 3 & ALL & Consolidation (13) & Abdominal sepsis & 78 & 2.3 & $4^{c}$ & - & Alive \\
\hline 4 & $A L L^{a}$ & Induction on ECMO & TRALI & 62 & 3.3 & 3 & - & Alive \\
\hline 5 & Burkitt lymphoma & Induction (16) & Pneumonia & 63 & 3.8 & 8 & - & Alive \\
\hline 6 & ALL & Allo SCT (31) & Pneumonia & 39 & 3.5 & 7 & Major & Died \\
\hline 7 & Hodgkin lymphoma & Allo SCT (33) & Pneumonia & 65 & 3.3 & 18 & - & Died \\
\hline 8 & ALL & Allo SCT (203) & Pneumonia & 68 & 3.3 & 10 & - & Died \\
\hline 9 & DLBCL & Induction on ECMO & Pneumonia & 102 & 4.0 & 4 & - & Died \\
\hline 10 & Multiple myeloma & Auto SCT (789) & Pneumonia & 43 & 3.7 & 9 & Major & Alive \\
\hline 11 & Anaplastic T-cell NHL ${ }^{a}$ & Induction on ECMO & Pneumonia & 46 & 3.0 & $25^{d}$ & Major & Alive \\
\hline 12 & $\mathrm{DLBCL}^{\mathrm{a}}$ & Induction on ECMO & $\mathrm{NHL}$ & 36 & 3.3 & $3^{c}$ & - & Alive \\
\hline 13 & $\mathrm{AML}$ & Consolidation (34) & Pneumonia & 48 & 3.3 & 34 & Major & Died \\
\hline 14 & $\mathrm{DLBCL}^{\mathrm{a}}$ & Induction on ECMO & $\mathrm{NHL}$ & 56 & 2.3 & $4^{d}$ & - & Alive \\
\hline
\end{tabular}

ALL, acute lymphoblastic leukemia; allo SCT, allogeneic stem cell transplantation; AML, acute myeloid leukemia; ARF, acute respiratory failure; auto SCT, autologous stem cell transplantation; CNS, central nervous system; DLBCL, diffuse large B-cell lymphoma; ECMO, extracorporeal membrane oxygenation; ICU, intensive care unit; LIS, lung injury score at ECMO baseline [30]; NHL, non-Hodgkin lymphoma; SAPS II, simplified acute physiology score at ICU admission [27]; TRALI, transfusion-related acute lung injury. ${ }^{\mathrm{a}}$ Diagnosis of hematologic malignancy on ECMO; ${ }^{\mathrm{b}}$ Two episodes of ECMO; ${ }^{\mathrm{c}}$ ventoarterial ECMO; ${ }^{\mathrm{d}}$ three episodes of ECMO.

large B-cell lymphoma, $n=3$; anaplastic T-cell lymphoma, $n=1$; central nervous system NHL, $n=1$ ), highly aggressive NHL in five (acute lymphoblastic leukemia, $n=4$ and Burkitt lymphoma, $n=1$ ), Hodgkin lymphoma in two, as well as acute myeloid leukemia and multiple myeloma in one patient each, respectively. The diagnosis of HM was established during ECMO support in four patients (patients 4,11,12, and 14). Five patients first received (immuno-) chemotherapy on ECMO, and four patients had recently received chemotherapy. Four patients had undergone ASCT within the previous year. Overall, seven patients were in the induction phase, six were in remission since 96 days (range, 39 to 292; patients 2, 3, 6 to 8 , and 13), and the patient with multiple myeloma was in partial remission. All patients but the latter had curative therapeutic options regarding their underlying HMs. For further information, see Table 1.

\section{Etiology of acute respiratory failure}

Etiology of ARF was pneumonia $(n=10)$, massive thoracic bulky disease with partial obstruction of bronchi, intrathoracic vessels, and the right heart $(n=2)$, as well as sepsis of nonpulmonary (abdominal) origin $(n=1)$, and transfusion-related acute lung injury $(n=1)$, respectively. Twelve patients fulfilled the criteria of severe ARDS. Microbiologic workup revealed pathogenic organisms in only three patients: Influenza A H1N1 $(n=2$, patients 10 and 13$)$ as well as histologically proven cytomegalovirus (CMV) infection $(n=1$, patient 8$)$. In two further patients, CMV infection was considered possible (massive replication of CMV copies in bronchoalveolar lavage fluid and plasma, patients 1 and 7). Diagnostic biopsies were performed on ECMO in five patients and revealed NHL $(n=2)$, CMV pneumonia $(n=1)$, and inconclusive results $(n=2)$. Autopsy was performed in five patients but did not reveal any further information on specific pathology or infections.

\section{Baseline characteristics}

At baseline, the median SOFA score was 12 (11 to 13), and LIS was 3.3 (3.3 to 3.7). All patients were receiving vasopressors, and one patient underwent continuous venovenous hemofiltration. Thrombocytopenia was present in 11 patients, with a median platelet count of 35 (26 to 51) $\mathrm{G} / \mathrm{L}$, and leukocytopenia was present in five patients with a median leukocyte count of 2.1 (1.8 to 2.5 ) G/L.

\section{ECMO therapy}

At the discretion of the treating intensivist, all but three patients were placed in the prone position before the start of VV ECMO. Decision for ECMO was then taken if the patient was still severely hypoxemic, or if ventilation was still unacceptably invasive.

Three patients received VA ECMO because, in addition to ARF, they presented with severe circulatory failure due to septic cardiomyopathy, leading to refractory left ventricular failure in one patient (patient 3) and lifethreatening right ventricular failure in two patients, one of them with an acute subtotal occlusion of the right pulmonary artery (patient 12), and one of them with acute 
superior vena cava syndrome and compression of the right heart due to DLBCL masses (patient 14).

All other patients received VV ECMO because of severe ARDS only. In one patient with a recent history of ASCT, ECMO was started before invasive mechanical ventilation with the intention of preventing intubation (patient 7). However, the patient had to be intubated on the subsequent day. ECMO therapy was used for a median of 8.5 (4 to 16) days, and mechanical ventilation, for 17 (12 to 35) days.

In patients with VV ECMO, percutaneous cannulation was performed by inserting a 21- to 24-F drainage cannula into a femoral vein and a 19 - to $22-\mathrm{F}$ into the right jugular vein by using the ultrasound-guided Seldinger technique. In one patient (patient 7), a 31-F double-lumen cannula was placed into the right jugular vein. In all three patients with VA ECMO, venous drainage cannulas were placed into a femoral vein, whereas the blood was returned via a femoral artery in two patients and via a right-sided subclavian patch in one patient (patient 12). Cannulation in VA ECMO was performed surgically by using a semiSeldinger cutdown technique. Sweep gas flow was set to achieve sufficient $\mathrm{CO}_{2}$ elimination, and the blood flow was set to achieve adequate systemic oxygenation or adequate circulatory support in VA ECMO patients.

Eleven patients received continuous intravenous infusion of unfractionated heparin to maintain an activated partial thromboplastin time of approximately 55 seconds. All but two of these patients additionally received antiplatelet therapy by intravenous prostaglandin $E_{1}$ at doses of 2.5 to $5 \mathrm{ng} / \mathrm{kg} / \mathrm{min}$. Three patients received subcutaneous low-molecular-weight heparin alone.

\section{Interventional procedures}

Both patients with circulatory failure due to massive intra-thoracic DLBCL masses were treated by interventional radiologists under emergency conditions on VA ECMO. The patient who presented with acute obstructive circulatory failure due to a highly compressed right pulmonary artery (patient 12) was treated with percutaneous implantation of a $16 \times 40$-mm self-expanding nitinol stent (sinus-XL; Optimed Medizinische Instrumente $\mathrm{GmbH}$, Ettlingen, Germany) into the mainstem of the pulmonary artery. In the patient with severe superior vena cava (SVC) syndrome (patient 14 ) a $24 \times 60-\mathrm{mm}$ sinus-XL stent was placed into the SVC by a transjugular access. In both patients, stent placement led to an immediate restoration of blood flows and, eventually, complete recovery of the circulatory failure.

\section{Bleeding events and other complications}

Major bleeding events were documented in five (36\%) patients from these locations: upper gastrointestinal tract $(n=3)$, nasopharynx, lung, and cannula insertion site (all in one patient), and multilocular intracerebral hemorrhages $(n=1)$. Of these, only the latter patient survived and experienced full neurologic recovery after discharge. In the four nonsurvivors, bleeding was part of multiorgan failure and not the primary reason for death. One patient with septic cardiomyopathy developed severe disseminated intravascular coagulation, leading to limb ischemia, and eventually needed amputation of both lower and one upper extremity. No thrombotic events were noted in any other patient (Table 1).

\section{Comparison of survivors with nonsurvivors}

Survivors had a significantly shorter time interval from diagnosis of the HM to the start of ECMO therapy, received less packed red blood cell units as well as single-donor platelet concentrates, and were less likely to have a history of ASCT. A trend for higher survival rates was noted in patients with shorter time intervals between ICU admission and start of ECMO therapy, shorter ECMO duration, and in patients in whom diagnosis of HM was made on ECMO. Conversely a trend for lower survival rates was noted in patients with higher LIS scores or $\mathrm{PaCO}_{2}$ levels at baseline, and in those with clinical signs of pneumonia (Table 2).

\section{Survival and hematologic outcome}

Survival off ECMO episodes was 59\% (10/17). One of the two patients with multiple episodes of ECMO survived and was discharged after the third application of ECMO, whereas the other patient died during the second ECMO episode. All patients with a history of ASCT died. Seven (50\%) patients survived the ICU and hospital stay. Their long-term survival was $100 \%$ after a median follow-up of 36 (10 to 58) months. At the time of the last visit, five survivors were in complete remission of their HM, whereas the patient with multiple myeloma remained in partial remission, and one patient with anaplastic T-cell lymphoma had experienced relapse. All but one patient in need of further antineoplastic treatment received the regularly scheduled number of chemotherapy courses without dose reduction.

\section{Discussion}

Recent data show impressive improvements in the outcomes of critically ill patients with HMs [1]. However, mortality rates still remain at $>50 \%$, if invasive mechanical ventilation becomes necessary because of ARF $[1,2,4,5,9]$. Thus, novel strategies to treat these patients are desperately needed. This is the first report on the use of ECMO in a series of patients with HMs and ARF. We observed a remarkable short- and long-term survival of $50 \%$, despite the presence of numerous factors known to be associated with adverse outcome [13]: First, all patients presented with at least three organ failures. Second, 
Table 2 Cohort characteristics and outcomes

\begin{tabular}{|c|c|c|c|c|}
\hline & All patients $N=14$ & Survivors $n=7$ & Nonsurvivors $n=7$ & $P$ value \\
\hline \multicolumn{5}{|l|}{ Characteristics at ICU admission } \\
\hline Age & $32(22-51)$ & $23(21-44)$ & $48(30-58)$ & 0.14 \\
\hline Male sex & 8 & 4 & 4 & 1.00 \\
\hline $\mathrm{CCl}$ & $2(2-2)$ & $2(2-2)$ & $2(2-4)$ & 0.48 \\
\hline SAPS $\|$ & $51(42-65)$ & $56(43-63)$ & $45(39-68)$ & 0.90 \\
\hline Prior allogeneic stem cell transplantation & 4 & 0 & 4 & $<0.01$ \\
\hline Days from diagnosis of $\mathrm{HM}$ to $\mathrm{ECMO}$ & $87(6-907)$ & $0((-1)-116)$ & $759(69-1,228)$ & 0.04 \\
\hline Days from ICU admission to ECMO & $2(0-3)$ & $1(0-2)$ & $3(1-11)$ & 0.08 \\
\hline Days from intubation to ECMO & $2(1-5)$ & $1(0-2)$ & $3(1-9)$ & 0.17 \\
\hline \multicolumn{5}{|l|}{ Characteristics at ECMO baseline } \\
\hline SOFA score & $12(11-13)$ & $12(12-19)$ & $12(11-15)$ & 0.79 \\
\hline Lung injury score & $3.3(3.3-3.7)$ & $3.3(2.3-3.7)$ & $3.5(3.3-3.8)$ & 0.09 \\
\hline $\mathrm{PaO}_{2} / \mathrm{FiO}_{2}$ ratio & $60(53-65)$ & $63(51-106)$ & $60(48-61)$ & 0.44 \\
\hline $\mathrm{pH}$ & $7.29(7.23-7.37)$ & $7.29(7.23-7.39)$ & $7.37(7.21-7.46)$ & 0.52 \\
\hline $\mathrm{PaCO}_{2}, \mathrm{~mm} \mathrm{Hg}$ & $49(43-59)$ & $41(38-49)$ & $55(48-72)$ & 0.05 \\
\hline Lactate, $\mathrm{m} M$ & $2.2(1.6-4.8)$ & $3.8(1.6-7.1)$ & $2.0(1.0-5.0)$ & 0.34 \\
\hline Hemoglobin, g/dl & $9.4(8.8-10.4)$ & $9.4(8.6-10.5)$ & $9.8(8.4-10.4)$ & 0.90 \\
\hline Leukocytes, G/L & $6.0(2.5-12.6)$ & $11.0(3.6-17.0)$ & $5.6(2.0-12.8)$ & 0.34 \\
\hline Platelets, G/L & $38(30-113)$ & $64(29-201)$ & $35(10-88)$ & 0.21 \\
\hline Prothrombin time, $\%$ & $70(43-74)$ & $50(18-72)$ & $73(64-78)$ & 0.22 \\
\hline Fibrinogen, mg/dl & $436(220-522)$ & $473(160-627)$ & $421(294-531)$ & 1.00 \\
\hline Etiology of ARF determined ${ }^{a}$ & 7 & 5 & 2 & 0.29 \\
\hline Clinical diagnosis of pneumonia & 10 & 3 & 7 & 0.07 \\
\hline \multicolumn{5}{|l|}{ Characteristics during ECMO } \\
\hline Venoarterial ECMO & 3 & 3 & 0 & 0.19 \\
\hline Duration of ECMO therapy, days & $8.5(4-16)$ & $4(3-9)$ & $10(7-28)$ & 0.08 \\
\hline Diagnosis of $\mathrm{HM}$ on ECMO & 4 & 4 & 0 & 0.07 \\
\hline Chemotherapy on ECMO & 5 & 4 & 1 & 0.27 \\
\hline Vasopressors & 14 & 7 & 7 & na \\
\hline Hemofiltration & 5 & 2 & 3 & 1.00 \\
\hline Major bleeding events & 5 & 1 & 4 & 0.27 \\
\hline Number of packed red blood cell units & $8(4-14)$ & $4(3-8)$ & $14(6-27)$ & 0.02 \\
\hline Number of platelet concentrates & $5(1-17)$ & $2(0-5)$ & $23(14-26)$ & 0.01 \\
\hline \multicolumn{5}{|l|}{ Outcome } \\
\hline ICU LOS, days & $22(14-42)$ & $22(21-77)$ & $18(11-40)$ & 0.12 \\
\hline Hospital LOS, days & $56(44-101)$ & $63(49-110)$ & $45(15-133)$ & 0.46 \\
\hline ICU and hospital survival, $n(\%)$ & $7(50 \%)$ & & & \\
\hline
\end{tabular}

Data are given as median and interquartile range or $n$, respectively; ARF, acute respiratory failure; $\mathrm{CCl}$, Charlson comorbidity index [26]; $\mathrm{HM}$, hematologic malignancy; ICU, intensive care unit; ECMO, extracorporeal membrane oxygenation; LOS, length of stay; na, not applicable; SAPS II, Simplified Acute Physiology Score at ICU admission [27]; SOFA score, Sequential Organ Failure Assessment Score at ECMO Baseline [29]; ${ }^{a}$ microbiologic pathogen detected or histologic proof of HM in lung biopsy.

intensive diagnostic efforts, including lung biopsy, failed to identify causative pathogens in almost all patients with pneumonia. Third, four (29\%) patients had undergone ASCT within the previous year. The finding that all four patients with a history of ASCT died, underlines the negative prognostic impact of allogeneic stem cell transplantation in critical illness. However, two of our patients may not have been good candidates for aggressive 
ICU management because of active graft-versus-host disease and thrombotic microangiopathy, which is known to be associated with poor outcome [31,32]. All of the 10 remaining patients fulfilled the criteria for a full-code ICU management, as recently proposed by an international expert consensus on critically ill cancer patients [13]. Their long-term survival was $70 \%$ even in the presence of multiorgan failure, severe and persistent thrombocytopenia, and/or leukocytopenia, multiple episodes of ECMO, the administration of chemotherapy, or other complex interventions before or during ECMO. Moreover, all but one surviving patient had favorable hematologic outcomes during the follow-up period.

The high rate of severe bleeding events (five (36\%) of 14) raises concerns about the safety of ECMO in patients with persistent thrombocytopenia. Importantly, four of five bleeding events occurred in the context of terminal multiorgan failure and were not likely to be the primary cause of death. However, according to our experience, keeping platelet count above the recommended threshold of $80 \mathrm{G} / \mathrm{L}$ [25] does not seem to be feasible in most patients with HMs. Thus, avoiding any additional risk factors for bleeding seems of major interest. We refrained from using any anticoagulation therapy for a total of 14 days in one persistently thrombocytopenic patient by using a heparin-coated system (HLS Set Advanced 7.0, Maquet Cardiopulmonary AG, Rastatt, Germany). The gas exchange remained excellent during the whole period, and no signs of hemolysis or coagulation activation were noted. To minimize the risk of bleeding in patients refractory to platelet transfusions, we suggest considering a "low or no" strategy concerning anticoagulation.

This study has several limitations. First, the retrospective design of the investigation does not allow conclusions concerning the efficacy of ECMO in these patients. Second, the number of patients is small. Third, our data reflect the experience of a single institution specifically devoted to the treatment of critically ill cancer patients and patients with ARDS, including extracorporeal lung support. Furthermore, it must be acknowledged that our cohort of patients represents only a very small proportion of critically ill HM patients with respiratory failure. Thus, our series is highly selective, and our findings may not be generalized.

Despite the promising results of our report, applying ECMO to patients with HMs cannot be regarded as an established therapy. Its efficacy and associated risks still remain to be established. Further research should focus on following questions: Which patients are likely to benefit from ECMO? When and under which circumstances should ECMO be initiated? What are the possible risks apart from complications associated with cannulation, infections, and bleeding events? Which measures must be taken to make ECMO as safe as possible in these vulnerable patients? Can ECMO be safely performed in spontaneously breathing patients with HMs and ARF to prevent endotracheal intubation?

Until these issues are settled, we propose to apply ECMO to patients with HMs exclusively under the following circumstances: (a) patients qualify for a full-code ICU management according to current recommendations on critically ill cancer patients [13], (b) lung-protective ventilation strategies, including supportive measures like prone positioning, result in inadequate gas exchange [24,33], (c) patients are included into yet to establish prospective research protocols, (d) a close cooperation of intensivists, hematologists, vascular surgeons, and perfusionists (if part of the local standard) is warranted, (e) general guidelines for the management of patients on ECMO are available and being followed [25], and (e) issues concerning anticoagulation and platelet transfusion are considered with special respect.

\section{Conclusions}

In conclusion, performing ECMO in carefully selected patients with HMs and severe ARF can be associated with favorable short- and long-term survival. This finding may even apply to patients with multiorgan failure, severe cytopenia, newly diagnosed HMs, as well as to those who need chemotherapy or complex interventional procedures on ECMO.

\section{Key messages}

- ECMO is feasible in patients with hematologic malignancies and acute respiratory failure.

- These patients are at increased risk for severe bleeding events.

- Short- and long-term survival may be significant in selected patients.

\section{Abbreviations}

ARDS: Acute respiratory distress syndrome; ARF: acute respiratory failure; ASCT: allogeneic stem cell transplantation; CCl: Charlson comorbidity index; DLBCL: diffuse large B-cell lymphoma; ECMO: extracorporeal membrane oxygenation; HM: hematologic malignancy; ICU: intensive care unit; LIS: lung injury score; NHL: non-Hodgkin lymphoma; SAPS II: Simplified Acute Physiology Score II; SOFA score: Sequential Organ Failure Assessment score; SVC: superior vena cava; VA: venoarterial; W: venovenous.

\section{Competing interests}

The authors declare that they have no competing interests.

\section{Authors' contributions}

PW contributed to conception and design of the study, acquisition and interpretation of the data, and drafted the manuscript. RU contributed to interpretation of the data. TS contributed to conception and design of the study, interpretation of the data, and helped to draft the manuscript. AB contributed to interpretation of the data. OR contributed to acquisition and interpretation of the data. AH contributed to acquisition and interpretation of the data. BL contributed to acquisition and interpretation of the data. NW contributed to acquisition and interpretation of the data. VF contributed to acquisition and interpretation of the data. MS contributed to acquisition and interpretation of the data and helped to draft the manuscript. 
MF contributed to acquisition and interpretation of the data. WR contributed to acquisition and interpretation of the data. PK contributed to interpretation of the data. KL contributed to interpretation of the data. GJL contributed to interpretation of the data, WRS contributed to interpretation of the data and helped to draft the manuscript. PS designed the study, contributed to acquisition and interpretation of the data, performed the statistical analysis, and drafted the manuscript. All authors read and approved the final manuscript.

\section{Authors' information}

Peter Schellongowski; on behalf of the Arbeitsgruppe für hämatoonkologische Intensivmedizin der Österreichischen Gesellschaft für Internistische und Allgemeine Intensivmedizin und Notfallmedizin (ÖGIAIN).

\section{Acknowledgements}

This study was founded in part by a research grant of Pfizer Corp. Austria.

\section{Author details}

'Department of Medicine I, Intensive Care Unit 13i2, Comprehensive Cancer Center, Medical University of Vienna, Waehringer Guertel 18-20, A-1090 Vienna, Austria. ${ }^{2}$ Department of Anaesthesia, Intensive Care Unit 13c2, Medical University of Vienna, Waehringer Guertel 18-20, A-1090 Vienna, Austria. ${ }^{3}$ Department of Bloodgroup Serology and Transfusion Medicine, Medical University of Vienna, Waehringer Guertel 18-20, A-1090 Vienna, Austria. ${ }^{4}$ Department of Medicine III, Intensive Care Unit 13h1, Medical University of Vienna, Waehringer Guertel 18-20, A-1090 Vienna, Austria. ${ }^{5}$ Department of Biomedical Imaging and Image-guided Therapy, Division of Cardiovascular and Interventional Radiology, Medical University of Vienna, Waehringer Guertel 18-20, A-1090 Vienna, Austria.

Received: 11 September 2013 Accepted: 27 December 2013 Published: 20 January 2014

\section{References}

1. Azoulay E, Mokart D, Pene F, Lambert J, Kouatchet A, Mayaux J, Vincent F, Nyunga M, Bruneel F, Laisne LM, et al: Outcomes of critically III patients with hematologic malignancies: prospective multicenter data from France and Belgium: A Groupe de Recherche Respiratoire en Reanimation OncoHematologique Study. J Clin Oncol 2013, 31:2810-2818.

2. Azoulay E, Recher C, Alberti C, Soufir L, Leleu G, Le Gall JR, Fermand JP, Schlemmer B: Changing use of intensive care for hematological patients: the example of multiple myeloma. Intensive Care Med 1999, 25:1395-1401.

3. Benoit DD, Vandewoude KH, Decruyenaere JM, Hoste EA, Colardyn FA: Outcome and early prognostic indicators in patients with a hematologic malignancy admitted to the intensive care unit for a life-threatening complication. Crit Care Med 2003, 31:104-112.

4. Schellongowski P, Staudinger T, Kundi M, Laczika K, Locker GJ, Bojic A, Robak O, Fuhrmann V, Jäger U, Valent $P$, Sperr WR: Prognostic factors for intensive care unit admission, intensive care outcome, and post-intensive care survival in patients with de novo acute myeloid leukemia: a single center experience. Haematologica 2011, 96:231-237.

5. Taccone FS, Artigas AA, Sprung CL, Moreno R, Sakr Y, Vincent JL: Characteristics and outcomes of cancer patients in European ICUs. Crit Care 2009, 13:R15.

6. Lecuyer L, Chevret S, Thiery G, Darmon M, Schlemmer B, Azoulay E: The ICU trial: a new admission policy for cancer patients requiring mechanical ventilation. Crit Care Med 2007, 35:808-814.

7. Azoulay E, Mokart D, Lambert J, Lemiale V, Rabbat A, Kouatchet A, Vincent F, Gruson D, Bruneel F, Epinette-Branche G, Lafabrie A, Hamidfar-Roy R, Cracco C, Renard B, Tonnelier JM, Blot F, Chevret S, Schlemmer B: Diagnostic strategy for hematology and oncology patients with acute respiratory failure: randomized controlled trial. Am J Respir Crit Care Med 2010, 182:1038-1046.

8. Azoulay E, Alberti C, Bornstain C, Leleu G, Moreau D, Recher C, Chevret S, Le Gall JR, Brochard L, Schlemmer B: Improved survival in cancer patients requiring mechanical ventilatory support: impact of noninvasive mechanical ventilatory support. Crit Care Med 2001, 29:519-525.

9. Gristina GR, Antonelli M, Conti G, Ciarlone A, Rogante S, Rossi C, Bertolini G Noninvasive versus invasive ventilation for acute respiratory failure in patients with hematologic malignancies: a 5-year multicenter observational survey. Crit Care Med 2011, 39:2232-2239.
10. Hilbert G, Gruson D, Vargas F, Valentino R, Gbikpi-Benissan G, Dupon M, Reiffers J, Cardinaud JP: Noninvasive ventilation in immunosuppressed patients with pulmonary infiltrates, fever, and acute respiratory failure. N Engl J Med 2001, 344:481-487.

11. Molina R, Bernal T, Borges M, Zaragoza R, Bonastre J, Granada RM, Rodriguez-Borregán JC, Núñez K, Seijas I, Ayestaran I, Albaiceta GM; the EMEHU study investigators: Ventilatory support in critically ill hematology patients with respiratory failure. Crit Care 2012, 16:R133.

12. Azoulay E, Afessa B: The intensive care support of patients with malignancy: do everything that can be done. Intensive Care Med 2006, 32:3-5.

13. Azoulay E, Soares M, Darmon M, Benoit D, Pastores S, Afessa B: Intensive care of the cancer patient: recent achievements and remaining challenges. Ann Intensive Care 2011, 1:5.

14. Peek GJ, Mugford M, Tiruvoipati R, Wilson A, Allen E, Thalanany MM, Hibbert CL, Truesdale A, Clemens F, Cooper N, Firmin RK, Elbourne D; CESAR trial collaboration: Efficacy and economic assessment of conventional ventilatory support versus extracorporeal membrane oxygenation for severe adult respiratory failure (CESAR): a multicentre randomised controlled trial. Lancet 2009, 374:1351-1363.

15. Noah MA, Peek GJ, Finney SJ, Griffiths MJ, Harrison DA, Grieve R, Sadique MZ, Sekhon JS, MCAuley DF, Firmin RK, Harvey C, Cordingley JJ, Price S, Vuylsteke A, Jenkins DP, Noble DW, Bloomfield R, Walsh TS, Perkins GD, Menon D, Taylor BL, Rowan KM: Referral to an extracorporeal membrane oxygenation center and mortality among patients with severe 2009 influenza A(H1N1). JAMA 2011, 306:1659-1668.

16. Gow KW, Wulkan ML, Heiss KF, Haight AE, Heard ML, Rycus P, Fortenberry JD: Extracorporeal membrane oxygenation for support of children after hematopoietic stem cell transplantation: the Extracorporeal Life Support Organization experience. J Pediatr Surg 2006, 41:662-667.

17. Gow KW, Heiss KF, Wulkan ML, Katzenstein HM, Rosenberg ES, Heard ML, Rycus PT, Fortenberry JD: Extracorporeal life support for support of children with malignancy and respiratory or cardiac failure: the extracorporeal life support experience. Crit Care Med 2009, 37:1308-1316.

18. Gorjup V, Fister M, Noc M, Rajic V, Ribaric SF: Treatment of sepsis and ARDS with extracorporeal membrane oxygenation and interventional lung assist membrane ventilator in a patient with acute lymphoblastic leukemia. Respir Care 2012, 57:1178-1181.

19. Liao WI, Tsai SH, Chiu SK: Successful use of extracorporeal membrane oxygenation in a hematopoietic stem cell transplant patient with idiopathic pneumonia syndrome. Respir Care 2013, 58:e6-e10.

20. Kasirajan V, Smedira NG, McCarthy JF, Casselman F, Boparai N, McCarthy PM: Risk factors for intracranial hemorrhage in adults on extracorporeal membrane oxygenation. Eur J Cardiothorac Surg 1999, 15:508-514.

21. Sun HY, Ko WJ, Tsai PR, Sun CC, Chang YY, Lee CW, Chen YC: Infections occurring during extracorporeal membrane oxygenation use in adult patients. J Thorac Cardiovasc Surg 2010, 140:1125-1132. e1122.

22. Pène $F$, Percheron $S$, Lemiale V, Viallon V, Claessens YE, Marqué $S$, Charpentier J, Angus DC, Cariou A, Chiche JD, Mira JP: Temporal changes in management and outcome of septic shock in patients with malignancies in the intensive care unit. Crit Care Med 2008, 36:690-696.

23. Stanworth SJ, Estcourt LJ, Powter G, Kahan BC, Dyer C, Choo L, Bakrania L, Llewelyn C, Littlewood T, Soutar R, Norfolk D, Copplestone A, Smith N, Kerr P, Jones G, Raj K, Westerman DA, Szer J, Jackson N, Bardy PG, Plews D, Lyons S, Bielby L, Wood EM, Murphy MF; TOPPS Investigators: A noprophylaxis platelet-transfusion strategy for hematologic cancers. N Engl J Med 2013, 368:1771-1780.

24. Ranieri VM, Rubenfeld GD, Thompson BT, Ferguson ND, Caldwell E, Fan E, Camporota L, Slutsky AS: Acute respiratory distress syndrome: the Berlin Definition. JAMA 2012, 307:2526-2533.

25. Extracorporeal Life Support Organization: Support EGfCEL. [http://www.elso. med.umich.edu]

26. Charlson ME, Pompei P, Ales KL, Mackenzie CR: A new method of classifying prognostic comorbidity in longitudinal studies: development and validation. J Chronic Dis 1987, 40:373-383.

27. Le Gall JR, Lemeshow S, Saulnier F: A new Simplified Acute Physiology Score (SAPS II) based on a European/North American multicenter study. JAMA 1993, 270:2957-2963.

28. Schellongowski P, Benesch M, Lang T, Traunmuller F, Zauner C, Laczika K, Locker GJ, Frass M, Staudinger T: Comparison of three severity scores for critically ill cancer patients. Intensive Care Med 2004, 30:430-436. 
29. Vincent JL, Moreno R, Takala J, Willatts S, De Mendonca A, Bruining H, Reinhart CK, Suter PM, Thijs LG: The SOFA (Sepsis-related Organ Failure Assessment) score to describe organ dysfunction/failure: on behalf of the Working Group on Sepsis-Related Problems of the European Society of Intensive Care Medicine. Intensive Care Med 1996, 22:707-710.

30. Murray JF, Matthay MA, Luce JM, Flick MR: An expanded definition of the adult respiratory distress syndrome. Am Rev Respir Dis 1988, 138:720-723.

31. Pène F, Aubron C, Azoulay E, Blot F, Thiéry G, Raynard B, Schlemmer B, Nitenberg G, Buzyn A, Arnaud P, Socié G, Mira JP: Outcome of critically ill allogeneic hematopoietic stem-cell transplantation recipients: a reappraisal of indications for organ failure supports. J Clin Oncol 2006, 24:643-649.

32. Afessa B, Azoulay E: Critical care of the hematopoietic stem cell transplant recipient. Crit Care Clin 2010, 26:133-150.

33. Guérin $C$, Reignier J, Richard JC, Beuret $P$, Gacouin $A$, Boulain $T$, Mercier $E_{1}$ Badet M, Mercat A, Baudin O, Clavel M, Chatellier D, Jaber S, Rosselli S, Mancebo J, Sirodot M, Hilbert G, Bengler C, Richecoeur J, Gainnier M, Bayle F, Bourdin G, Leray V, Girard R, Baboi L, Ayzac L; PROSEVA Study Group: Prone positioning in severe acute respiratory distress syndrome. $N$ Engl J Med 2013, 368:2159-2168.

doi:10.1186/cc13701

Cite this article as: Wohlfarth et al: Extracorporeal membrane

oxygenation in adult patients with hematologic malignancies and severe acute respiratory failure. Critical Care 2014 18:R20.

\section{Submit your next manuscript to BioMed Central and take full advantage of:}

- Convenient online submission

- Thorough peer review

- No space constraints or color figure charges

- Immediate publication on acceptance

- Inclusion in PubMed, CAS, Scopus and Google Scholar

- Research which is freely available for redistribution 